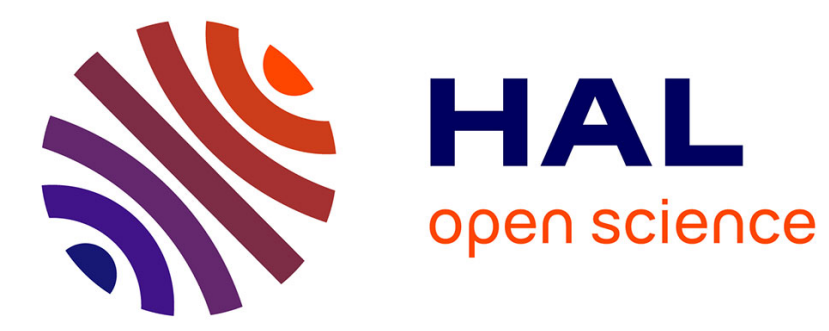

\title{
Sensorless control of Switched Reluctance Machine
}

\author{
Abdoulaye Sarr, Imen Bahri, Demba Diallo, Éric Berthelot
}

\section{To cite this version:}

Abdoulaye Sarr, Imen Bahri, Demba Diallo, Éric Berthelot. Sensorless control of Switched Reluctance Machine. IECON 2016 - 42nd Annual Conference of the IEEE Industrial Electronics Society, Oct 2016, Florence, Italy. pp.6693 - 6698, 10.1109/IECON.2016.7793584 . hal-01495230

\section{HAL Id: hal-01495230 \\ https://hal-centralesupelec.archives-ouvertes.fr/hal-01495230}

Submitted on 12 Mar 2020

HAL is a multi-disciplinary open access archive for the deposit and dissemination of scientific research documents, whether they are published or not. The documents may come from teaching and research institutions in France or abroad, or from public or private research centers.
L'archive ouverte pluridisciplinaire HAL, est destinée au dépôt et à la diffusion de documents scientifiques de niveau recherche, publiés ou non, émanant des établissements d'enseignement et de recherche français ou étrangers, des laboratoires publics ou privés. 


\title{
Sensorless Control of Switched Reluctance Machine
}

\author{
Abdoulaye SARR, Imen BAHRI Member, IEEE, Demba DIALLO Senior Member, IEEE, Eric BERTHELOT \\ Group of Electrical Engineering - Paris (GeePs), \\ (CNRS, CentraleSupélec, UPMC, Univ. Paris-Sud) 91192 Gif Sur Yvette, France \\ abdoulaye.sarr@centralesupelec.fr
}

\begin{abstract}
The Switched Reluctance Machine is one of the most promising electrical machine in variable speed applications because of its intrinsic robustness and its fault tolerant capability. However, the performances of the machine are deteriorated when a defect affects the position sensor. This paper describes a sensorless control for the switched reluctance machine: two methods based on the characteristics of the machine are proposed to eliminate the requirement of the position sensor. The first one utilizes the phase inductance characteristic to determine the rotor position by injecting a test signal while the phase winding is non-energized. The second one utilizes the flux characteristic to estimate the position by measuring the phase voltage and current. Both methods are evaluated through intensive simulation and the results show their good performance respectively in low speed and high speed region. The flux-based method, implemented in a FPGA, has been evaluated on a test bed. The experimental results confirm the simulation ones with an average position estimation error of around $2^{\circ}$ mechanical in the range between $1 / 3$ and the rated speed.
\end{abstract}

Keywords - Switched reluctance machine, Sensorless control, DSP, FPGA, flux characteristics, inductance characteristics

\section{INTRODUCTION}

Due to the progress of power electronics and the improvement of computerized design methods, there is an increasing trend of using electric machines in industrial applications and transportation. Until recently the permanent magnet synchronous machines and the induction machines were mostly used due to their energy efficiency. Recently, the Switched Reluctance Machine (SRM) is becoming more and more popular as it's considered as a good candidate for automotive applications as well as for wind energy conversion systems [1] [2].

The SRM is characterized by its simple geometrical construction its robustness and rugged structure that make it very attractive. It has also a low cost and a high efficiency over a wide speed range. The SRM has also the particularity that the phase characteristics are independent which makes it extremely fault tolerant for critical applications. However, despite these advantages, the use of the SRM is strongly penalized by its acoustic noise and high torque ripple. The origin of the noise can be mechanic, magnetic, electronic and aerodynamic. A lot of work is being done to reduce the noise and the torque ripples [3] [4].

Moreover, like the other synchronous machines, the control of the SRM requires that the rotor position is known. Generally, a mechanical encoder is used to measure the position. The elimination of this position sensor would reduce the cost and the packaging requirements of the drive. It could also increase the reliability of the SRM. The use of a virtual sensor (an algorithm) to retrieve the rotor position is known as sensorless control. In [5] the state of the art in sensorless technology for the SRM is presented. Many interesting publications are reported in researches in recent years, but until now, none of them have yet succeeded in eliminating completely the sensor without deteriorating the performances. The general principle of all the published sensorless control methods of SRM exploits the characteristics of the machine such as the flux-linkage or the phase inductance to estimate the position. In [6] a sensorless control of switched reluctance motor based on phase inductance vectors is proposed. This method does not require a priori knowledge on magnetic characteristics of SRM. Based on the pulse injection technique, it proposes a technique called phase current slope difference for identifying the phase inductance then a full-cycle phase inductance subregional method combined with orthogonal decomposition of the phase inductance is proposed to estimate the rotor position. This method is relatively easy to implement, it does not require additional hardware and complex computation. However, it needs a huge amount of memory. In [7] the authors propose a simple impedance sensing method for SRM position estimation based on the inductance characteristic. This method is intended to enhance the classic pulse injection technique by applying judiciously voltage pulses in the region of minimum inductance. This method is more efficient for low and medium speed applications. Fluxphase based methods for estimating the rotor angle are presented in [8] [9]. They exploit the flux-current characteristic of the SRM. With the measurements of terminal voltages and phase currents, the flux linkage is calculated and the position information is obtained using a look-up table. These methods have generally better performance at high speed. There is also a wide variety of position estimators using artificial neural network [10] [11], fuzzy logics [12] [13] and observers [14] [15]

In this paper, the authors propose two methods to estimate the rotor position. In fact, the goal is to combine the two methods to provide continuous rotor position on a wide speed range with the best performances. The first one, named inductancebased method is an active one as it consists of applying a voltage pulse on a non-energized phase and measuring the phase current to estimate the phase inductance. The rotor position is processed from the inductance curve. The second one, named flux-based method, is a passive one as it uses the current measurement and the flux to estimate the rotor position. Simulation and experimental results of this method are presented and discussed. FPGA-based implementation of the 
second method is provided and results prove the effectiveness of the proposed methods.

The paper is organized as follows: In section II we present the structure and the operation principle of the switched reluctance machine. The principle of the two proposed methods and their simulation results are presented in section III and IV. Experimental results for the flux-based method are given in section V. A conclusion and discussions on future works close the paper.

\section{BASIC PRINCIPLES OF SRM}

The switched reluctance machine is an electromechanical energy converter. Its operation is based on the principle of minimum reluctance. When one phase is excited, the rotor tends to move to a position where the flux of the exciting phase is maximized.

The SRM is a double salient machine. Both its stator and its rotor are salient. The stator has $N_{s}$ salient poles with concentred field coils. The rotor contains $N_{r}$ passive salient poles, it does not have coils or permanent magnets, it is entirely composed of ferromagnetic material. In this paper an $8 / 6$ four phases SRM is considered. Assuming that the phases are independent, the mutual coupling is very small and can be neglected. The stator winding can be excited by a converter. Many converter topologies have been investigated, but the Half Bridge Asymmetric Converter is the most used due to its simplicity and its robustness. The SRM voltage phase can be expressed as:

$$
U=R i+\frac{d \varphi(\theta, i)}{d t}
$$

An expanded form of (1) is given by:

$$
U=R i+L(\theta, i) \frac{d i}{d t}+e
$$

Where, $U$ is the phase voltage, $i$ is the phase current, $R$ is the winding resistance, $\theta$ is the rotor position, $\omega$ is the angular velocity, $\varphi(\theta, i)$ phase flux linkage, $L(\theta, i)$ is the inductance and $e$ represents the back-emf defined as:

$$
e=i \omega \frac{\partial L}{\partial \theta}
$$

Due to the double saliency of the SRM, the flux linkage is a nonlinear function of the current and the rotor position. The flux- curve obtained by finite element analysis is shown in Fig. 1. The inductance curve $L(\theta, i)$ for different values of current and rotor position is represented in Fig. 2. The principle of the two sensorless methods presented in this paper exploits these two characteristics to estimate the position.

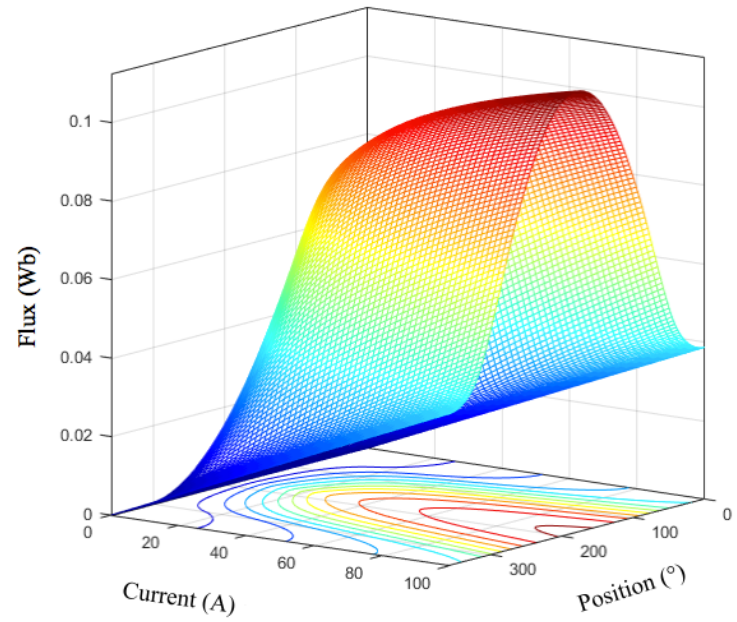

Fig. 1. Flux-linkage characteristics of SRM

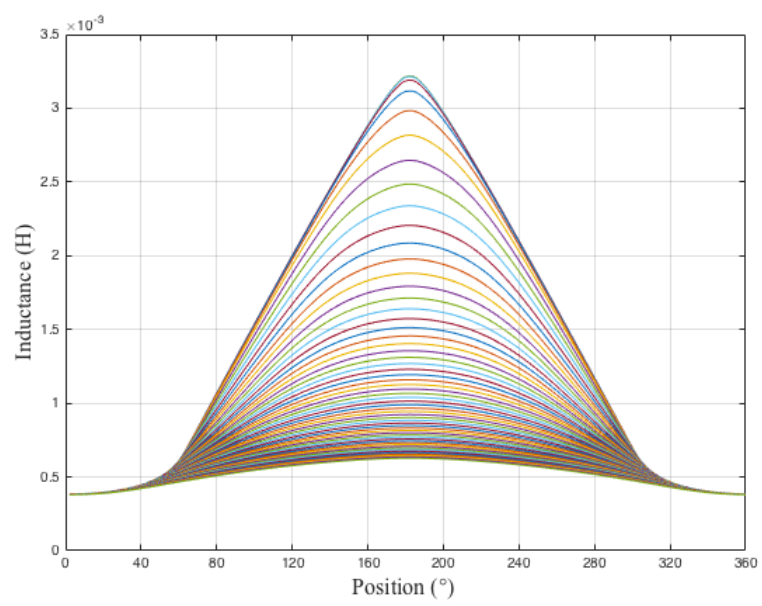

Fig. 2. Inductance characteristics of SRM

The instantaneous phase torque of the SRM is given by:

$$
T_{e}=\frac{1}{2} i^{2} \frac{d L(\theta, i)}{d \theta}
$$

The SRM controller requires the on-line position information and phase currents.

\section{INDUCTANCE-BASED METHOD FOR SRM POSITION ESTIMATION}

In this section an intrusive method based on the inductance curve is presented, which is more suitable for low speed operation. As shown in Fig.3, when a phase is non-energized, we can inject a high frequency voltage pulse $U$. At low speed, if the pulse period $\Delta T$ is short enough, the resulting peak current $i_{\text {peak }}$ remains small, thus the voltage drop in the phase winding $R . i$ and the back-emf $e$ can be neglected. The phase voltage equation (2) becomes:

$$
U=L \frac{i_{p e a k}}{\Delta T}
$$



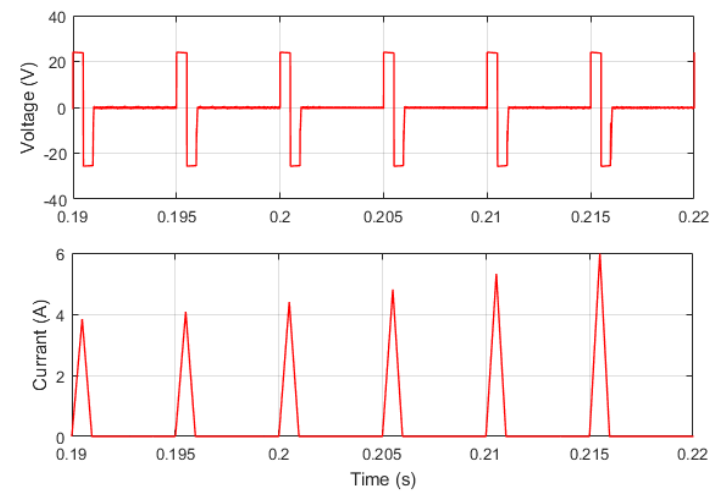

Fig. 3. Principle of pulse injection

The phase inductance value $\hat{L}$ is estimated from the peak current $i_{\text {peak }}$ and the characteristics of the voltage pulse ( $U=$ $24 \mathrm{~V}$ and $\Delta T=0.5 \mathrm{~ms})$. It is expressed as:

$$
\hat{L}=U \frac{\Delta T}{i_{\text {peak }}}
$$

The rotor position $\hat{\theta}$ is then obtained by using the inductance characteristic (Fig.2) as an inverse function.

$$
\hat{\theta}=f^{-1}\left(\hat{L}, i_{\text {peak }}\right)
$$

The injection is done alternatively in the four phases and a mapping is done to continuously monitor the rotor position from the four estimated values as displayed in Fig. 4. This method is simple to implement and does not require extra circuit because the pulse is injected by the main converter.

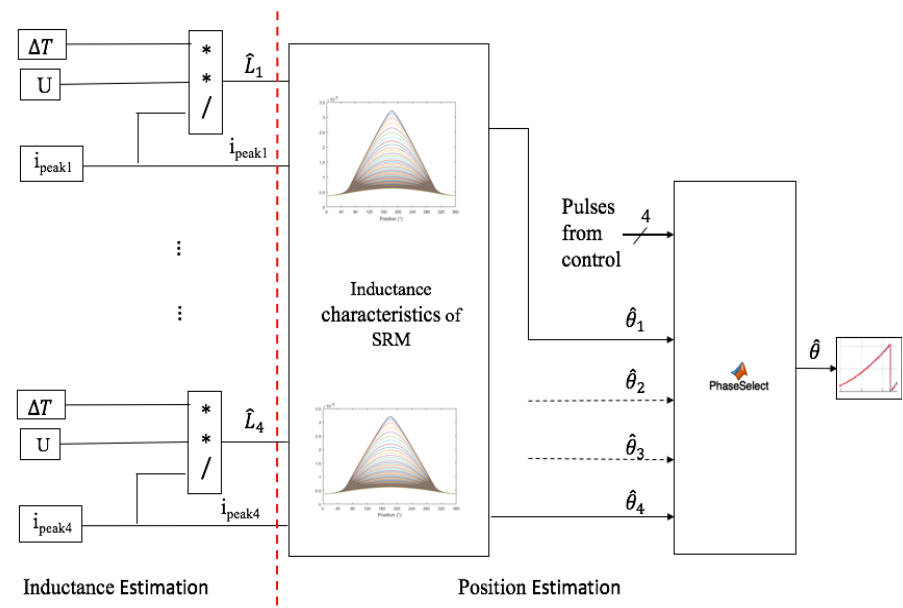

Fig. 4. Block diagram for the four-phase SRM position estimation

To evaluate this method, its performances are analyzed by simulation using Matlab-Simulink. The simulation results are obtained using a four phases 8/6 SRM. Fig. 5 shows the current waveforms in the four phases. The phases are sequentially excited by injecting short pulses when the main current is zero. Each phase is excited for $90^{\circ}$ electrical $\left(15^{\circ}\right.$ mechanical $)$ and gives the position information during $90^{\circ}$ of an electrical cycle.
Fig. 6 shows from top to bottom the speed waveform, the actual and estimated positions and the position error. It shows that the error increases with the speed. In fact, when the speed increases, the number of pulses during an electrical cycle is reduced and becomes insufficient to accurately estimate the position. Moreover, the back-emf also increases, so the approximation in (5) is no longer valid. Moreover, the pulses are injected in a non-energized phase. While the inductance is decreasing, a negative torque may arise and there are also additional Joule losses that deteriorate the global efficiency of the system. Therefore, this method will be accurate in low speed range. The average position estimation error is $1.5^{\circ}$ at $150 \mathrm{rpm}$ and $4^{\circ}$ at $360 \mathrm{rpm}$ at steady state.
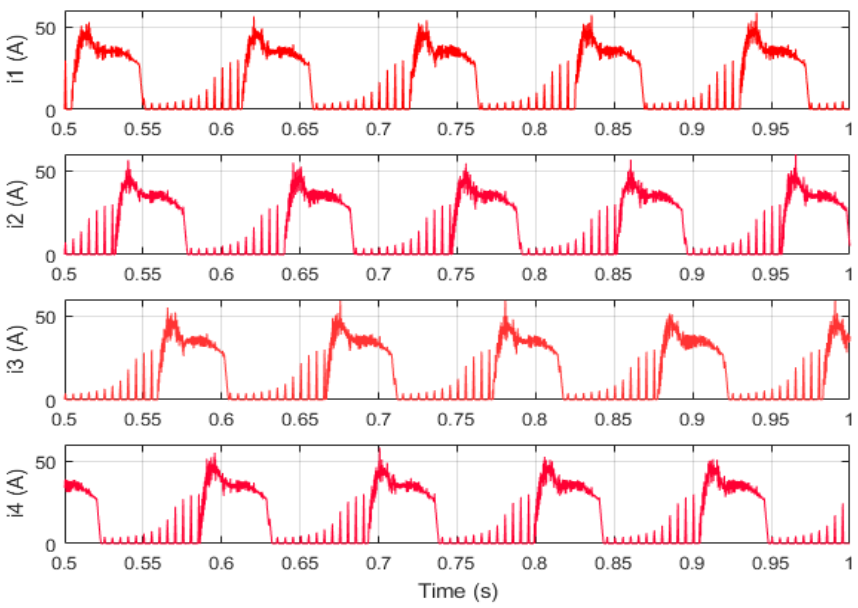

Fig. 5. Four-phase current waveforms
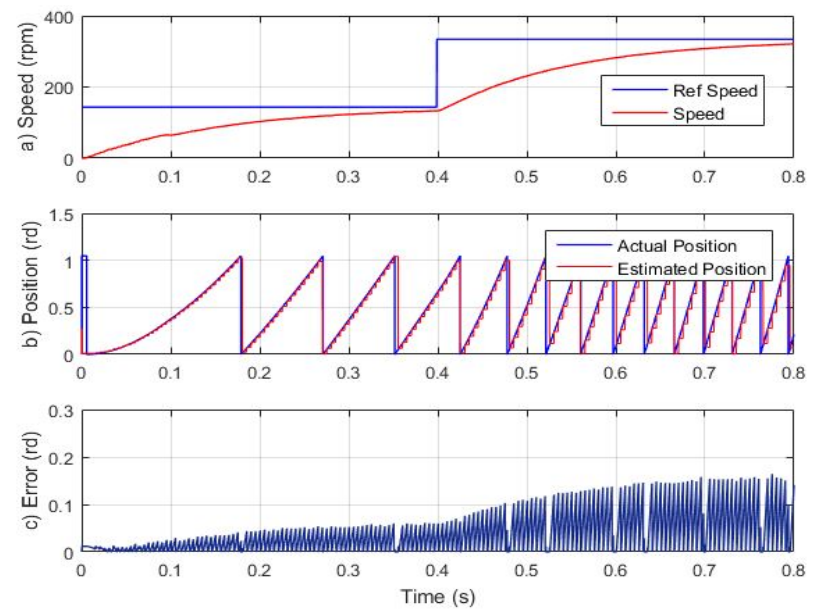

Fig. 6. Influence of the speed

To evaluate the load torque effect on the estimation at low speed (100 rpm), a variable load torque from no load to $50 \%$ of the nominal torque is introduced. As it can be observed in Fig. 7 , the estimation error increases slightly but remains very low, less than $0.05 \mathrm{rd}$.

As a partial conclusion, the speed is the main limitation for this method. 

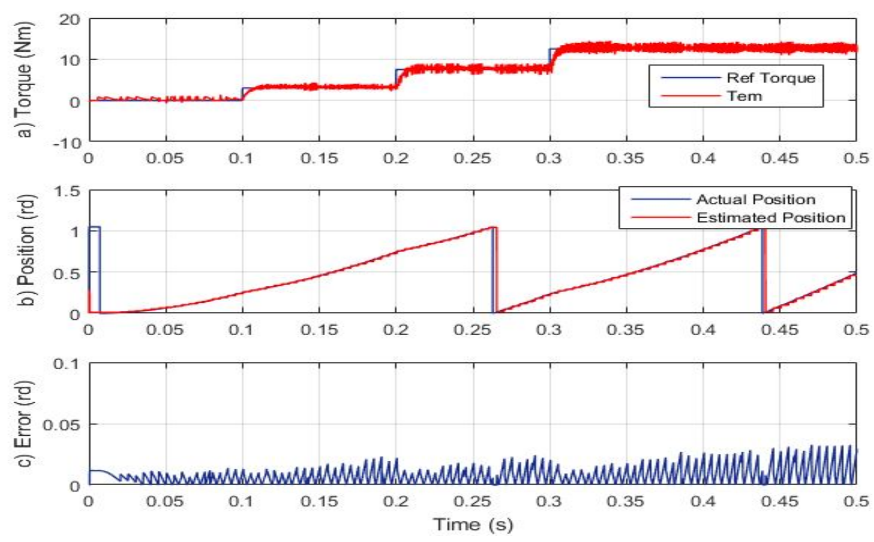

Fig. 7. Influence of the load torque

\section{FluX- Based Method for SRm Position Estimation}

The flux method is a passive (or non-intrusive) method. Its principle is based on the already available measurements of the phase current and voltage to estimate the flux linkage by integration:

$$
\varphi=\int(U-R i) d t
$$

The position can be estimated using the flux characteristic presented in Fig. 1 as a multidimensional look up table.

$$
\theta=f^{-1}(\varphi, i)
$$

The method is applied for each phase and a mapping is also done to retrieve continuously the rotor position from the four estimates as displayed in Fig.8. The main difficulty of this method is to estimate accurately the flux by integration of the chopping voltage at low speed. This sensorless method is therefore preferably used at higher speed when the machine operates in single mode. The accuracy of this method depends on the accuracy of both the flux determination and the flux characteristic. It also highly depends on the performance of the digital signal processor (sampling time and data storage capability).

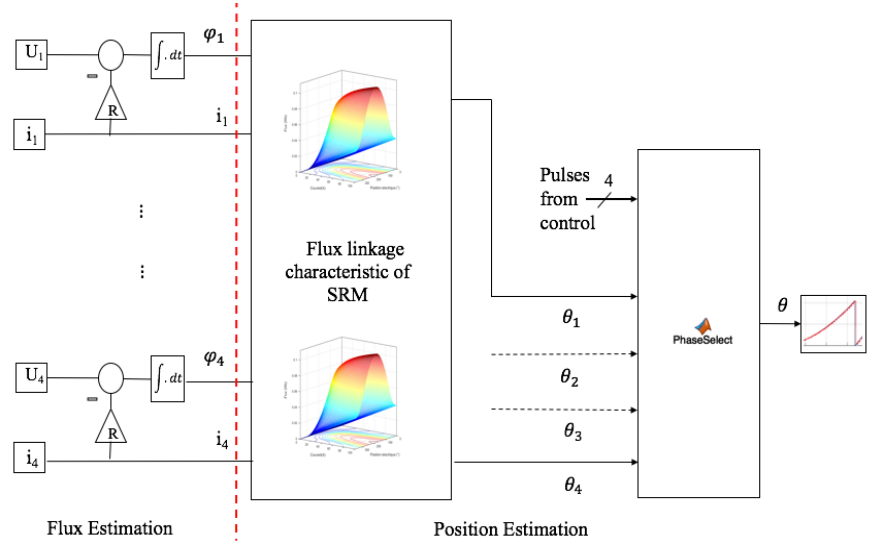

Fig. 8. Position estimation based on flux linkage computation
The phase voltage is not measured; it is derived from the switching states of the half bridge converter. Only current sensors are used and hysteresis controller is used to regulate the current.

The performance of this method is then analysed by MatlabSimulink simulation. As in the former case, the influence of the speed and the load torque on the estimation error accuracy is presented. The purpose of the simulation is to determine the accuracy of the flux-based method over a large speed range with a variable load. From top to bottom, Fig. 9 displays the rotating speed, the phase 1 current and flux linkage.
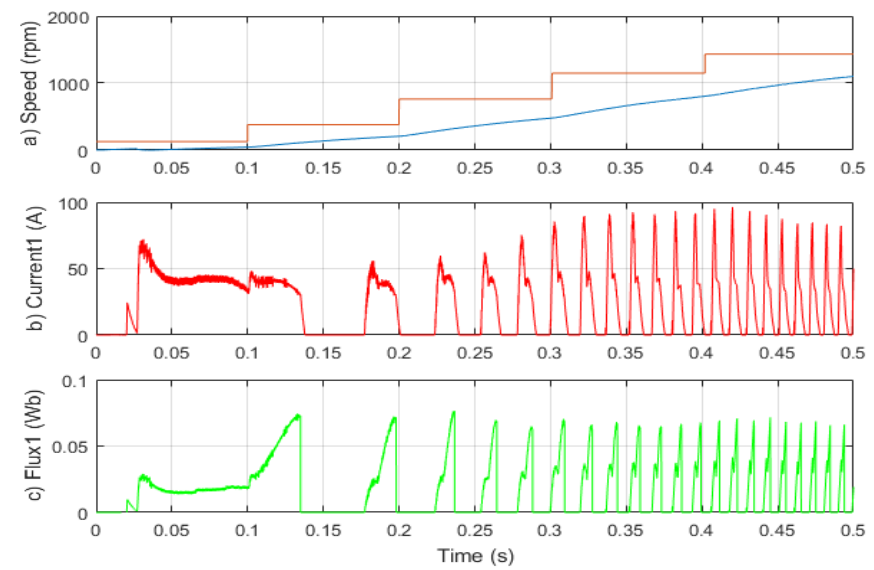

Fig. 9. Speed, phase current and flux linkage waveforms

Fig. 10 illustrates the performances of the estimation method. Simulation results show a good agreement between the estimated and actual position with an average error of $1.9^{\circ}$ mechanical. The accuracy is improved when the speed increases.
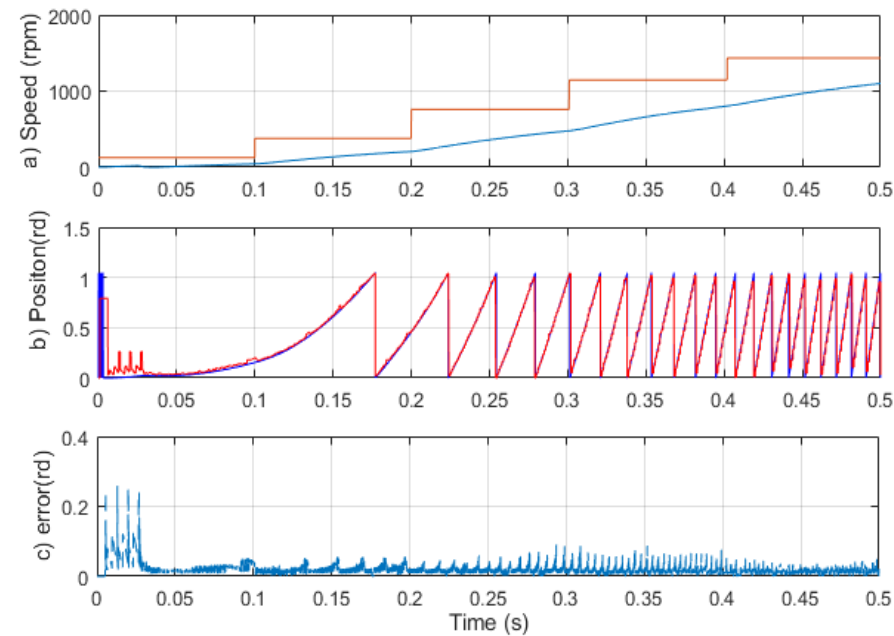

Fig. 10. Speed, actual and estimated position, position error

Fig. 11 shows the results of an increasing load applied to the SRM at $1000 \mathrm{rpm}$. We can observe a better estimation for higher load torque with an average error of $1.2^{\circ}$ mechanical. 

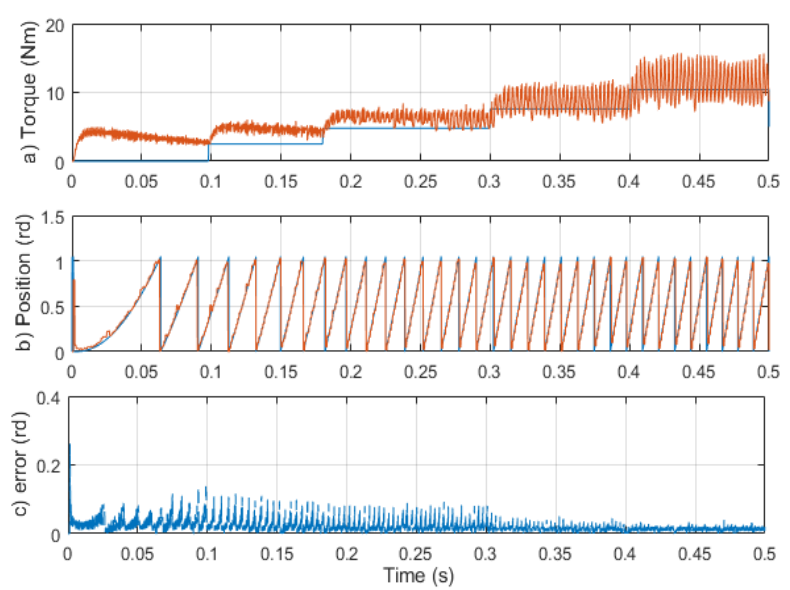

Fig. 11. Electromagnetic and load torque, actual and estimated position, position error

\section{EXPERIMENTAL SETUP AND RESULTS}

This section presents the experimental setup and the experimental results of the position estimation based on the flux method. Figure 12 displays the experimental test bed, which also includes a PC for programming (Matlab-Simulink) and supervision (Control-Desk). The machine is a four-phase 8/6 SRM, which characteristics are given in the appendix. The SRM speed is controlled through an outer speed loop and an inner hysteresis current loop. An asymmetric half bridge converter with IGBT switches is used to feed the machine. To evaluate the performance of the flux-based method, an incremental encoder is used to compare the estimated position with the measured rotor position. A DC motor and a powder brake are coupled to the SRM as a variable load. The digital controller is composed of a Digital Signal Processor DS1005 and FPGA chip. The DSP is used for the speed control loop and the communication while the FPGA is used for implementation of current regulators and flux estimation.

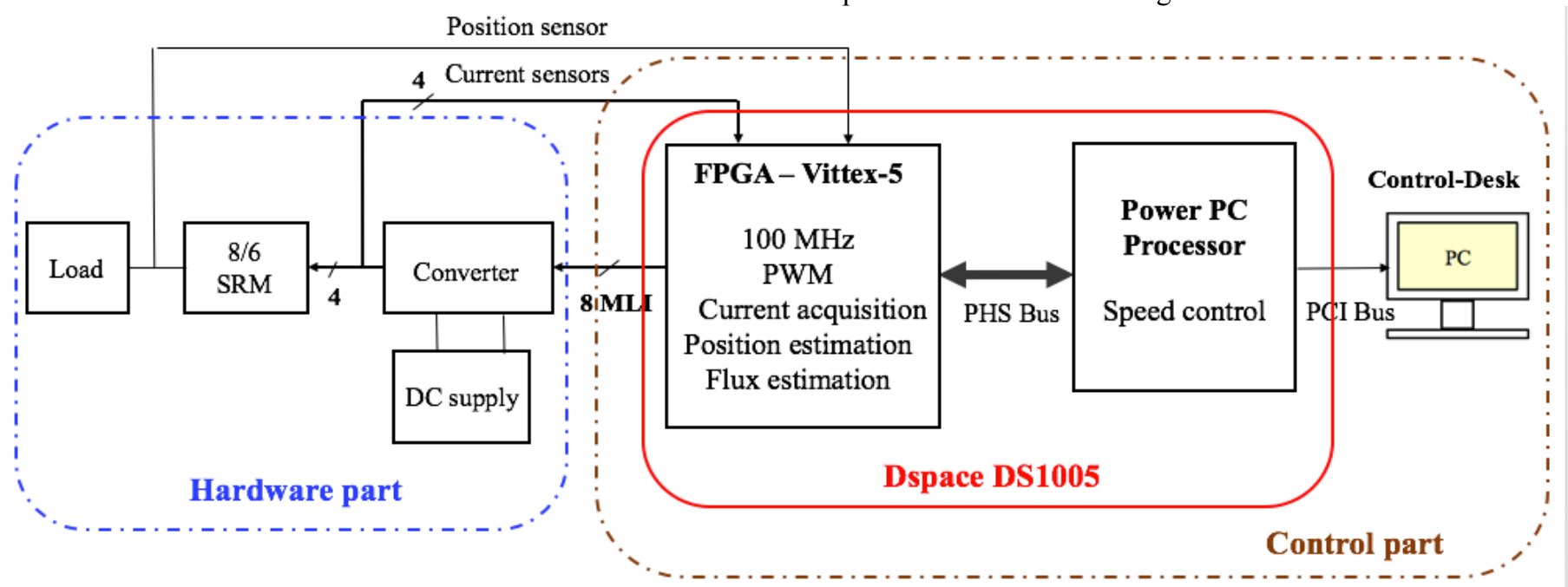

Fig. 12. Block diagram of the SRM experimental setup

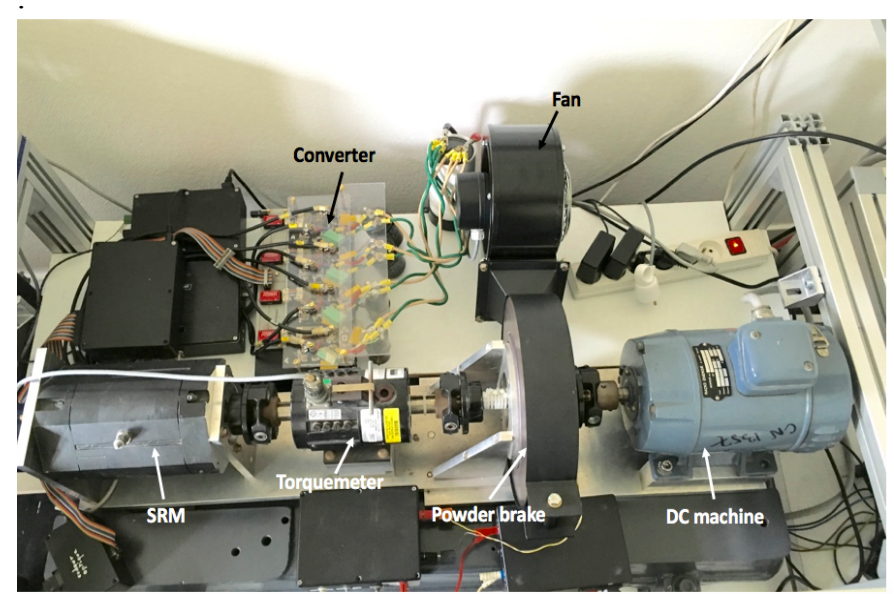

Fig. 13. Experimental SRM drive
Fig. 14 displays the experimental results of the flux-based position estimation at steady state for different speeds; the load torque is set at $5 \mathrm{Nm}$ ( $25 \%$ of the nominal load). The curves represent the measured rotor position, the estimated position and the instantaneous mechanical position error (radian). These experimental results show that the flux-based algorithm implemented in the FPGA is promising. However, it should be mentioned that the results might be degraded at low speed by glitches in the estimated signal position. This phenomenon appears when the algorithm switches from one phase to another. In this four-phase $8 / 6 \mathrm{SRM}$ a glitch is susceptible to appear every $15^{\circ}$ mechanical. Fortunately, the duration of the glitch is very short and may not affect the control. In addition, this phenomenon disappears at high speed, as shown in Fig. 14d. The average position error around $2^{\circ}(0.04$ radian $)$, which is $0.6 \%$, fits with the requirements of many applications. 
a) Speed $=800 \mathrm{rpm}$
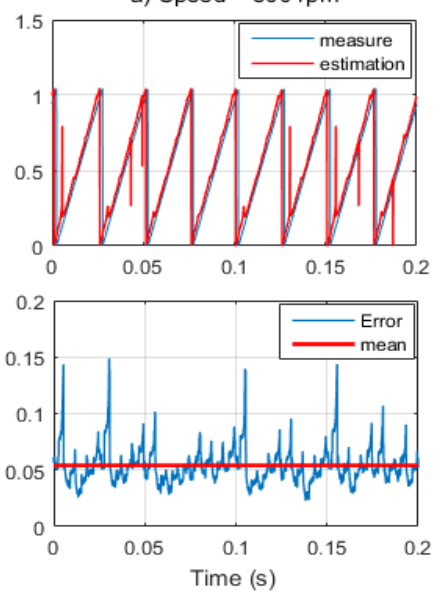

a) $800 \mathrm{rpm}$
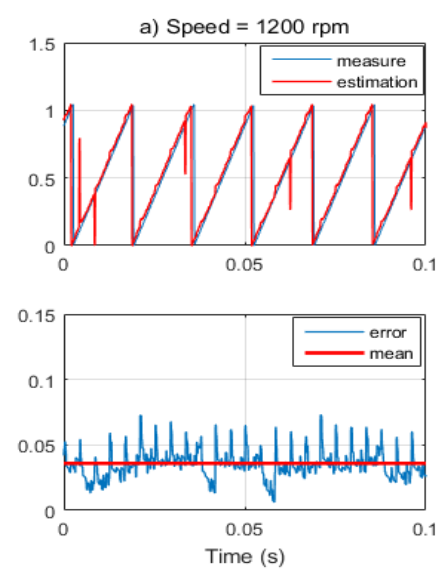

c) $1200 \mathrm{rpm}$
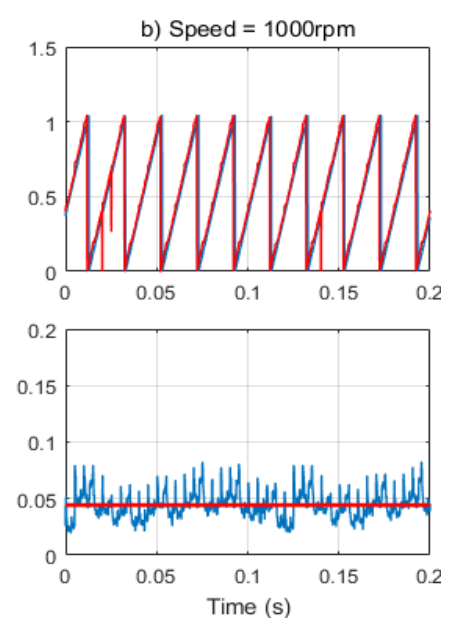

b) $1000 \mathrm{rpm}$
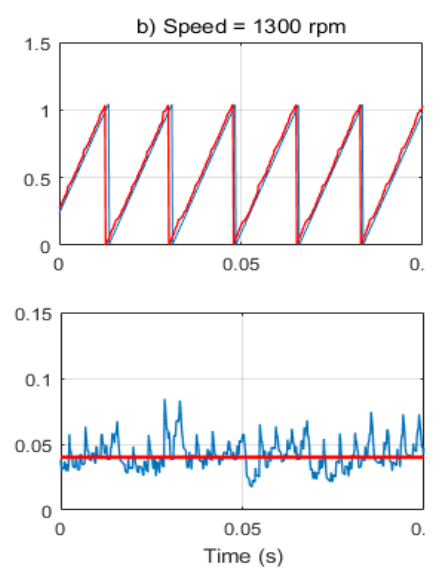

d) $1300 \mathrm{rpm}$

Fig. 14. Position estimation experimental results with flux-based method

\section{CONClusions AND PERSPECTIVES}

This paper dealt with the sensorless control of the SRM. After the description of the fundamental principles of the inductance-based method (active) and the flux-based method (passive), they have been both evaluated in simulation. These results have shown that the inductance-based method is efficient in low speed region and that the flux-based one is more efficient in high speed region. We have also studied their robustness to load torque variation and pointed out the issues for their implementation (required sensors for example). An experimental test bed has been presented and the first estimation results presented for the flux-based method implemented in a FPGA while the control is implemented in a DSP. They confirm the simulation results as the average position estimation error is around $2^{\circ}$ mechanical in the range between $1 / 3$ and the rated speed. It is obvious that the active and passive methods are complementary; therefore, the next step is the experimental validation of the inductance-based approach and the combination of both methods to estimate the rotor position on the whole speed range and for all load torques. Robustness to parameter variations (winding resistance, sampling period eg.) should also be evaluated.

\section{APPENDIX}

\section{CHARACTERISTICS OF THE SRM}

\begin{tabular}{|l|c|}
\hline Number of stator poles & 8 \\
\hline Number of rotor poles & 6 \\
\hline Number of phases & 4 \\
\hline Nominal Torque & $25 \mathrm{Nm}$ \\
\hline Rated power & $1200 \mathrm{~W}$ \\
\hline Rated speed & $3000 \mathrm{tr} / \mathrm{mn}$ \\
\hline
\end{tabular}

\section{REFERENCES}

[1] H. Chen, J. J. Gu, "Implementation of the Three-Phase Switched Reluctance Machine System for Motors and Generators," in IEEE/ASME Transactions on Mechatronics, vol. 15, no. 3, pp. 421-432, June 2010.

[2] Iqbal Husain, Switched reluctance machines, The university of Akron, 2002 by CRC Press LLC

[3] M.N. Anwar, I. Husain, "Radial force calculation and acoustic noise prediction in switched reluctance machines", IEEE Transactions on Industry Applications, vol. 36, no. 6, pp.1586-1597 Nov/Dec 2000.

[4] C. Lin, S. Wang, B. Fahimi, "Efficient multiphysics modelling of vibration and acoustic noise in switched reluctance motor drives," IECON-40th Annual Conference of the IEEE Industrial Electronics Society, Dallas, TX, 2014, pp. 542-548, 2014.

[5] M. Ehsani, B. Fahimi, "Elimination of position sensors in switched reluctance motor drives: state of the art and future trends," in IEEE Transactions on Industrial Electronics, vol. 49, no. 1, pp. 40-47, Feb 2002

[6] J. Cai, Z. Deng, "Sensorless control of switched reluctance motor based on phase inductance vectors," in IEEE Transactions on Power Electronics, vol. 27, no. 7, pp. 3410-3423, July 2012.

[7] K. Xin, Q. Zhan, J. Luo, "A new simple sensorless control method for switched reluctance motor drives," 2005 International Conference on Electrical Machines and Systems vol. 1, pp. 594-598, 2005

[8] W. Zeng, C. Liu, Q. Zhou, J. Cai, L. Zhang, "A new flux/current method for SRM rotor position estimation," Electrical Machines and Systems, ICEMS. International Conference on, pp. 1-6, Tokyo, 2009,

[9] Q. Q. Ma, W. H. Liang, F. J. T. E. Ferreira, D. Q. Bi, B. M. Ge, "Improved flux linkage method for position sensorless control of highspeed SRM," Electrical Machines (ICEM), International Conference on, pp. 783-788, Berlin, 2014.

[10] C. A. Hudson, N. S. Lobo, R. Krishnan, "Sensorless control of single switch-based switched reluctance motor drive using neural network," in IEEE Transactions on Industrial Electronics, vol. 55, no. 1, pp. 321-329, Jan. 2008.

[11] R. Zhong, Y. B. Wang, Y. Z. Xu, "Position sensorless control of switched reluctance motors based on improved neural network," in IET Electric Power Applications, vol. 6, no. 2, pp. 111-121, February 2012.

[12] A. D. Cheok, Zhongfang Wang, "Fuzzy logic rotor position estimation based switched reluctance motor DSP drive with accuracy enhancement," IEEE Transactions on Power Electronics, vol. 20, no. 4, pp. 908-921, July 2005.

[13] Yu-Long Cui, Jiao-Min Liu, Xue-Chuan Hou and Xiao-Ying Zhao, "Improvement of rotor position angle estimation in SRD using fuzzy logic based motor model," Machine Learning and Cybernetics, 2003 International Conference on, 2003, pp. 2726-2730 Vol.5.

[14] P. Brandstetter, P. Krna, "Sensorless control of switched reluctance motor using sliding mode observer," Applied Electronics (AE), International Conference on, pp. 1-4, Pilsen, 2013.

[15] A. Khalil et al., "Four-quadrant pulse injection and sliding mode observer based sensorless operation of a switched reluctance machine over entire speed range including zero speed," Fourtieth IAS Annual Meeting. Conference Record of the Industry Applications Conference, vol. 3, pp. 2147-2154, 2005. 